Running head: MONEY AND OBJECTIFICATION

The Love of Money Results in Objectification

Xijing Wang and Eva G. Krumhuber

University College London

Author Note

Xijing Wang and Eva G. Krumhuber, Department of Experimental Psychology, University College London, United Kingdom.

We thank Kathleen Vohs for her valuable comments on an earlier draft of this paper.

Correspondence concerning this article should be addressed to Xijing Wang,

Department of Experimental Psychology, University College London, 26 Bedford Way

London WC1H 0AP, United Kingdom. E-mail: xijing.wang.13@ucl.ac.uk

Word count: 7203 


\begin{abstract}
Objectification, which refers to the treatment of others as object-like things, has long been observed in capitalism. Whilst the negative impact of money on interpersonal harmony has been well documented, the social cognitive processes that underlie them are relatively unknown. Across four studies, we explored whether the love of money leads to objectification, while controlling for social power and status. In Study 1, the love and importance attached to money positively predicted the tendency to construe social relationships based on instrumentality. In Study 2, the likelihood to favor a target of instrumental use was increased by momentarily activating an affective state of being rich. Temporarily heightening the motivation for money further resulted in deprivation of mental capacities of irrelevant others, including humans (Study 3) and animals (Study 4). This lack of perceived mental states partially mediated the effects of money on subsequent immoral behavior (Study 4). The findings are the first to reveal the role of objectification as a potential social cognitive mechanism for explaining why money often harms interpersonal harmony.
\end{abstract}

Keywords: money, market-pricing mode, objectification, instrumentality, mental state, immorality. 


\section{The Love of Money Results in Objectification}

As one of the greatest inventions, money has brought profound changes and convenience to economic trade. However, when it comes to interpersonal relationships, money has been found to have a dark underbelly by increasing selfishness and 'breeding' unethical behavior (e.g. Gino \& Pierce, 2009; Tang \& Chen, 2008; Tang, Chen, \& Sutarso, 2008). Specifically, money reduces pro-sociality (Pfeffer \& DeVoe, 2009), compassion in the face of others' misfortunes (Molinsky, Grant, \& Margolis, 2012), and the ability for emotional inference and perspective taking (Caruso, Mead, \& Vohs, 2009; Ma-Kellams \& Blascovich, 2013). These effects are robust as even using subtle reminders of money (e.g., exposure to money-related words and images) can lead to negative consequences such as cheating (Kouchaki, Smith-Crowe, Brief, \& Sousa, 2013) and a reduction in helpful behavior (Vohs, Mead, \& Goode, 2006; for a review see Vohs, 2015). Despite consistent findings about the detrimental effects of money, little is known about the underlying social cognitive processes that justify such conduct. In this article, we explore a novel mechanism for explaining the unethical and undesirable interpersonal outcomes brought about by money: objectification.

\section{Definition of Objectification}

The tendency to view and treat others as objects can be considered as one of the most deleterious forms of prejudice (Nussbaum, 1999). Among the many facets of objectification, two have been proposed as central to its definition: 1) treating a target as a means to one's ends (i.e. instrumentality) and 2) depriving the target of its essential humanity such as mental state capacities (i.e. agency, autonomy, and subjectivity, Nussbaum, 1995; Papadaki, 2007; Loughnan et al., 2010). Within social relationships, people typically value and are likely to approach targets who display traits that facilitate interaction and bonding, such as similarity, interpersonal warmth, and kindness (Berscheid \& Reis, 1998). When a target is objectified, these personal attributes migrate to the background in favor of the target's usefulness. During 
this process, the person is figuratively split into parts, with only those traits being seen as valuable that can serve a perceiver's current goal (Gruenfeld, Inesi, Magee, \& Galinsky, 2008). In a similar way to that in which the process applies to objects, the person then becomes a means to one's ends and is reduced to the status of a tool for goal achievement. Besides the instrumentality assumption, objectification also refers to the denial of agency, autonomy, and subjectivity (Nussbaum, 1995). One of the fundamental conditions to be seen as fully human lies in the capacity for having complex mental states (Papadaki, 2007; Loughnan et al., 2010). These typically include cognitive abilities (e.g. agency, autonomy) as well as fundamental experiences and feelings (e.g., joy, pain; Gray, Young, \& Waytz, 2012). Due to their biological nature, living entities such as human and animals, are by default perceived as possessing mental states, although the level of such capacities may vary (e.g. Bastian, Loughnan, Haslam, \& Radke, 2012; Penn \& Povinelli, 2007). When objectification occurs, however, targets are seen as lacking respective capacities, hence being likened to mindless objects.

Such withdrawal of others' mental states could further facilitate a third aspect of objectification, namely violability (i.e., lack in boundary integrity, Nussbaum, 1995). Mental state attributions have been highlighted as an essential ingredient for considering a target as worthy of moral concern (Gray et al., 2012). If a target is deprived of its mental abilities that make it a part of the moral community, immoral actions towards objectified targets become permissible. In line with this argument, violability in the form of immoral actions displayed towards sexualized human targets or food animals was found to be the result of lower state mind-attributions (e.g., Bastian et al., 2012; Loughnan et al., 2010).

Whereas it has been well-documented that women are often sexually objectified (e.g. Gervais, Vescio, Förster, Maass \& Suitner, 2012; Loughnan, et al. 2010; Vaes, Paladino, \& Puvia, 2011), object-like treatment of all humans occurs in a number of domains (for a 
review, see Haslam, 2006). Of interest for the present research endeavor, economists and sociologists have long posited the existence of objectification in the economic system (e.g. Blauner, 1964). For instance, under capitalism where the most prominent aim is to increase wealth, workers have been considered to be mere instruments that can be reduced to their work productivity (Marx, 1844). Recent empirical studies point toward the link between objectification and power (Gruenfeld et al., 2008; Gwinn, Judd, \& Park, 2013; Inesi, Lee, \& Rios, 2014). Besides the fact that employees commonly act in the role of power receivers, objectification rises with specific features of factory work and a focus on the instrumentality of work-related attributes (Andrighetto, Baldissarri, \& Volpato, 2016; Baldissarri, Andrighetto, \& Volpato, 2014). Such economic valuation of human targets in labor markets can further reduce activity in brain networks related to social cognition (e.g. medial prefrontal cortex; Harris, Lee, Capestany, \& Cohen, 2014).

The findings provide significant insights into objectification within the economic domain. Nonetheless, it remains difficult to differentiate between multiple concepts (i.e. economic interests, social power, status) that may be intertwined in driving respective processes. The present work addresses this issue by investigating whether the sole desire for money, one of the most prevalent phenomenon in capitalism as well as in everyday life, leads to objectification.

\section{Money and Objectification}

Given that money functions as a tool for economic exchange, there exists a strong association between money and its utility (Lee, Lee, Bertini, Zauberman, \& Ariely, 2015). Correspondingly, monetary thoughts activate a mindset of market-pricing in which social relations are seen in transactional terms with inputs (costs) and expected outputs (benefits) (Fiske, 1992). Such costs and benefits can be defined in monetary terms (e.g. price, commission, and wage), but can also take more abstract forms (e.g. mental effort, time, and 
care). In this vein, Heyman and Ariely (2004) showed that the effort exerted in helping others was directly proportional to the magnitude of anticipated reward once this economic mindset was activated.

Importantly, self-gain acts as the fundamental motive in economic reasoning, which in turn translates to a focus on goal achievement (Baumeister \& Vohs, 2016). To maximize personal benefits, one needs to effectively calculate how others could facilitate its fulfillment. For this, a utilitarian view is adopted in which social targets are considered to be relevant if their attributes are congruent with one's current goal. Similar to what happened under objectification, the usefulness of the target then becomes a defining feature that determines the construal of the relationship. Monetary thoughts could therefore lead to objectification by encouraging people to focus on a target's instrumental use for goal attainment.

In parallel, money might foster a mindset that increases disregard of those who do not facilitate self-gain and achieving a goal. Indeed, money has been shown to increase one's distance from others, both physically and mentally (Ma-Kellams \& Blascovich, 2013; Vohs, Mead, \& Goode, 2008), and impede perspective-taking and compassion (e.g. Caruso et al., 2009; Molinsky et al., 2012). To minimize costs and input, money could therefore undermine motives to perceive a mind in irrelevant targets. This may result in the denial of subjectivity so as to conserve mental energy for attending to more useful information. Given that mind attribution is an essential ingredient for moral concern (Gray et al., 2012), lower subjectivity as a result of monetary thoughts could further pave the way for violable, unethical behavior.

\section{Aims of Present Research}

A predominant goal in capitalism is to increase wealth (Marx, 1844) which is well reflected in the value ascribed to money. The current research aimed to examine whether the desire for money (i.e. love of money) leads to objectification. Love of money reflects the combined notions of the importance attached to money (cognition), the desire to be rich 
(affect), and the motivation to pursue money (Tang \& Chiu, 2003; Tang \& Chen, 2008). In line with previous works, we focused on the affective and motivational aspects in the love of money (for an overview see Baumeister \& Vohs, 2016). To assess this construct, we measured people's attitudes toward money with a combined money scale in Study 1, and subsequently manipulated love of money by eliciting an affective state of being rich (Study 2) or activating the motivation to increase money (Studies 3 and 4).

By definition, love of money is not equal to one's objective need for money (Tang \& Chiu, 2003), which is often determined by a person's financial resources or wealth. While previous studies consistently revealed a negative impact of money on ethicality and interpersonal harmony, inconsistencies still exist with respect to whether money independent of socioeconomic status leads to immorality and mental state deprivation (Hall, Mast, \& Latu, 2015; Kraus, Côté, \& Keltner, 2010; Piff, Stancato, Côté, Mendoza-Denton, \& Keltner, 2012; Tang \& Chiu, 2003). Only one past study has examined the direct link between love of money and unethicality via a calculation-based mindset, i.e. Machiavellianism (Tang \& Chen, 2008). The trait measure of Machiavellianism, however, relates more to a personality syndrome of employing manipulative and devious methods for personal goal achievement (Wilson, Near, \& Miller, 1996).

To fill this empirical gap in the literature, the present research aims to provide the first evidence for the relationship between love of money and objectification by controlling for socioeconomic status. It does so by considering multiple dimensions of objectification, namely instrumentality, denial of mental states, as well as violability. Furthermore, it highlights the role of mental state attribution in explaining subsequent immoral and violent behaviors caused by money.

To that end, we first aim to investigate the link between love of money and the instrumentality dimension of objectification. We predict that the love and importance attached 
to money enhance the tendency to view relationships with others as instrumental (Study 1).

Furthermore, the affective state of being rich, by thinking about a lifestyle of sheer abundance, should make people more likely to choose targets based on their instrumental use to achieve a goal (Study 2). Secondly, we aim to explore whether the love of money leads to the denial of mental states in irrelevant targets, which in turn may function to justify further immoral behaviors. For this, we predict that the motivation for money, by thinking about ways to increase seed money, would make participants more likely to deprive others of their mental capacities. Based on evidence showing that people apply a unifying cognitive template for mind perception and morality concerns across species (see Gray et al., 2012), this effect should generalize to human targets (Study 3) and animals (Study 4). Lastly, we examined whether mental state attribution ultimately mediates the effect of money on unethical behavior (Study 4).

\section{Study 1: Self-Report of Objectification}

Study 1 was designed to test whether there exists a link between love of money and instrumentality as a form of objectification. To this end, the full money scale by Lim and Teo (1997) together with a subscale of the YTF Money Scale (Baker \& Hagedorn, 2008) were employed to measure people's attitudes toward money. In addition, we used the objectification scale by Gruenfeld et al. (2008) which measures the extent to which relationships are viewed as instrumental. To rule out the potential influence of extraneous variables, we included measures of social power and socioeconomic status.

\section{Method}

Participants. One hundred and eighteen (105 women, $M_{\text {age }}=24.2, S D=9.55$ ) participants (55\% Caucasian, 33\% Asian, and 12\% others) were recruited through the undergraduate psychology subject pool $(N=58)$ and via a psychological research website $(N$ 
$=60$ ). Participants took part in this study in exchange for course credits or on a voluntary basis. Informed consent was obtained from all participants prior to their participation.

Design and Procedure. The study was conducted online using Qualtrics survey software. After reading the instructions and providing some general demographic information, participants first completed the 10-item Objectification Scale (Gruenfeld et. al., 2008) that was modified to assess the extent to which people perceive general others (rather than one specific person) as instrumental and their relationships as contingent on goal state. Example items were "I always approach those people who are very useful to me" and "If something changes and a person won't be helpful to me anymore, my relationship with this person won't continue". All items were rated on 7-point Likert scales where $1=$ strongly disagree and $7=$ strongly agree. A scale score was calculated by averaging all items, with higher scores indicating higher degrees of objectification $(\alpha=.63)$.

Participants then completed the 34-item Money Scale (Lim \& Teo, 1997) which measures various aspects of money attitudes in the form of eight subscales: obsession, power, budget, achievement, evaluation, anxiety, retention, and non-generosity. Example items were "Money is the most important goal in my life" (obsession) and "Money gives you autonomy or freedom" (power). To assess the degree to which money is used for signaling one's power, importance and achievement, we further included the 11-item power-prestige subscale from the YTF Money Scale (i.e. a combined scale of Yamauchi and Templer's MAS Scale and Furnham's MBBS scale, Baker \& Hagedorn, 2008). Example items were "I use money to influence people to do things for me" and "I am proud of my financial victories - pay, riches, investments, etc. - and let my friends know about them.” All items were rated on 7-point Likert scales where $1=$ strongly disagree and $7=$ strongly agree. A total score was computed as the mean of all 45 items, with higher scores reflecting greater importance attached to money $(\alpha=.90)$. 
Next, socioeconomic status was assessed through three items: (a) the social status ladder (Adler, Epel, Castellazzo, \& Ickovics, 2000) ranging from 1= the lowest standing to 10 $=$ the highest standing, (b) educational level (twelve options from $1=$ no schooling completed to 12 = doctorate degree), and (c) total household income (fourteen options from $1=$ less than $£ 6000 / \$ 10,000$ to $14=£ 150,000 / \$ 250,000$ or more $).$

Lastly, participants completed the 8-item Sense of Power Scale (Anderson \& Galinsky, 2006) which measures an individual's general sense of power and influence over others in relationships (e.g., "If I want to, I get to make the decisions"). Items were endorsed on 7-point Likert scales, from $1=$ strongly disagree to $7=$ strongly agree. A scale score was computed as the average of all items, with higher scores indicating stronger perceptions of personal power $(\alpha=.81)$. For all measures, items within each scale were presented in a random order.

\section{Results and Discussion}

Correlational analyses showed that the tendency to objectify others in relationships significantly increased with the subjective importance attached to money, $r(118)=.37, p<$ .001. When the money subscales were examined separately, five aspects of money attitudes significantly correlated with the degree of objectification: obsession $(\alpha=.76), r(118)=.47, p$

$<.001$; power $(\alpha=.68), r(118)=.31, p=.001$; achievement $(\alpha=.74), r(118)=.26, p=$ .004 ; anxiety $(\alpha=.67), r(118)=.26, p=.004$; and power-prestige $(\alpha=.82), r(118)=.49, p$ $<.001$ (see Table 1). In a multiple regression, money obsession, $\beta=.28, t(113)=2.44, p=$ .016 , and money power-prestige, $\beta=.28, t(113)=2.39, p=.018, F(2,113)=21.1, R^{2}=.26$, $p<.001$, emerged as the sole predictors of objectification among all measures, including general sense of power and socioeconomic status (i.e. social status, educational level, and income). Thus, respondents' inclination to objectify others by viewing their relationships as 
instrumental could be significantly predicted by their propensity to obsess about money and believe in money prestige.

\section{Study 2: Choice of Work Partner}

The first study provided preliminary evidence for the association between money attitudes and objectification. Specifically, money obsession and money power-prestige, both of which signify the love and importance attached to money (Tang \& Chiu, 2003) acted as significant predictors of the instrumentality dimension of objectification. This was shown when controlling for the potential impact of socioeconomic status and sense of power. In a second study, we aimed to corroborate and extend the findings by exploring the causal effects of love of money on objectification.

To test whether objectification increases with money as an affective value (i.e. affect toward being rich), participants either imagined living a life of sheer affluence (money condition) or described their ordinary daily life (control condition). Subsequently, they were given a goal to conduct a science project, for which a choice needed to be made between two work partners that differed in their usefulness. We predicted that the affective state of being rich increases the tendency to favor the target of instrumental use by shifting the focus from personal traits to a goal contingent trait. For the purpose of replication, we included measures of social power and socioeconomic status again.

\section{Method}

Participants. Ninety-two participants (41 women, $\left.M_{a g e}=31.5, S D=8.9\right)(76 \%$ Caucasian, $6 \%$ Hispanic, $4 \%$ Black, and $14 \%$ others) were recruited from public areas in central London (i.e., public libraries and cafeterias) and took part in the study on a voluntary basis. Data from eight participants were excluded due to incompleteness or failure to follow instructions in the writing task ${ }^{1}$. Participants were randomly assigned to one of two conditions 
(money vs. control), resulting in forty-one people in the money condition and forty-three in the control condition. Informed consent was obtained from all people prior to their participation.

Design and Procedure. The study was described as a two-part study with unrelated segments and was completed on paper. In the first part, participants completed a writing task. To elicit the affective state of being rich (money condition), they were asked to imagine becoming a big lottery winner and living a life of sheer abundance. As such, they could use the money to achieve a life that they have ever dreamed of and do things that they have always wanted to (see Vohs et al., 2008 for similar instructions). In the control condition, they described their ordinary daily activities and routines. In both conditions, participants had to describe a typical day in this life and write at least 250 words about what they would do, where they would go, and how they would feel. To measure social power, participants reported after the writing task how much control and influence they had experienced over other people in the scenario described, using 9-point Likert scales ranging from 1 (not at all) to 9 (extremely).

In the second part of the study, a decision task adapted from Gruenfeld et al. (2008) was used to assess instrumentality in partner choice. Participants were provided with a written scenario in which they were given a goal to accomplish a science project. For this goal, they had to choose between two work partners: (a) a useful but callous Partner A - "good at science-based subjects but cold and unkind", or (b) a kind but useless Partner B - "warm and kind but not good at science-based subjects". Preferences in terms of partner choice were indicated using a 6-point Likert scale (1 = strongly prefer A, $2=$ prefer A, $3=$ slightly prefer $A, 4=$ slight prefer $B, 5=$ prefer $B$, and $6=$ strongly prefer $B)$. The matching between alphabets (A or B) and partners (useful or kind) was counterbalanced across participants. Responses were coded so that lower scores indicated higher preferences for the useful partner. 
Lastly, participants answered the same three questions about their socioeconomic status as in Study 1 .

\section{Results and Discussion}

In line with predictions, participants in the money condition $(M=3.44, S D=1.38)$ revealed a stronger preference to work with the useful but unkind partner than those in the control condition $(M=4.35, S D=1.48), t(82)=-2.91, p=.005, d=0.64$. Money as a desirable good with affective value (i.e., affect toward being rich, Tang \& Chiu, 2003) consequently led to greater instrumentality in the construal of relationships with others. The subjective feeling of influence was higher in the money condition $(M=7.10, S D=1.50)$ compared to the control condition $(M=6.47, S D=1.33), t(82)=2.05, p=.044, d=0.45$. However, when controlling for social power (control, influence) and socioeconomic status in an analysis of covariance (ANCOVA), the effect of condition (money vs. control) on instrumental partner preference remained significant, $F(1,75)=11.0, p=.001, \eta_{\mathrm{p}}{ }^{2}=.13$, thereby ruling out alternative explanations. Together, the first two studies showed that love of money leads to the treatment of others as a means to one's end, by construing relationships based on people's instrumentality and goal congruent traits.

\section{Study 3: Mind Perception of Human Faces}

While the focus of the previous two studies was on instrumentality, in subsequent experiments (Studies 3 and 4) we planned to study the effect of money on the second essential dimension of objectification, namely the deprival of mental states (Nussbaum, 1995; Gray et al., 2012). In addition, we aimed to explore the role of money as a motivator (i.e. pursuing money). Besides the greater relevance in terms of incentive structures of money experienced in everyday life, it allowed us to investigate the motivational mechanisms involved in the love of money. To this end, participants were presented with facial images varying in realism 
which they had to evaluate with respect to their mental state capacities. We hypothesized that target faces would need to look more realistic in order to be perceived as human when participants had been thinking of ways to increase seed money (money condition) compared to daily travel plans (control condition). For the purpose of replication, measures of social power and socioeconomic status were included again.

\section{Method}

Participants. Ninety-two White Caucasian participants (44 women, $M_{a g e}=30.9, S D=$ 7.37) were recruited from a public library in central London and took part in the study on a voluntary basis. Data from seven participants were excluded due to failure to follow instructions in the writing task. Participants were randomly assigned to one of two conditions (money vs. control), resulting in forty-three people in the money condition and forty-two people in the control condition. Informed consent was obtained from all people prior to their participation.

Stimuli. Facial stimuli were taken from Krumhuber, Swiderska, Tsankova, Kamble, and Kappas (2015) and featured three Caucasian male targets that had been selected from a pool of ten male identities. A pilot study $(N=30)$ showed that there were no significant differences between the three male targets in terms of perceived attractiveness $(M=1.84)$, intelligence $(M=2.58)$, trustworthiness $(M=2.39)$, and likeability $(M=2.32 ; 5$-point scale, all $p \mathrm{~s}>.05)$. By morphing between human realistic and artificial (i.e., stylized) versions of each target face, image sequences were obtained that displayed equal increments of physical change between the human and artificial endpoint. For the present study, we selected images from seven points spaced across the morph sequence, resulting in nine variants for each facial identity (1 human, 7 morphs, and 1 artificial) (see Figure 1A). The resulting 27 facial stimuli (3 identities x 9 variants) were displayed in color on white background and measured $400 \mathrm{x}$ 380 pixels. 
Design and Procedure. The study was described as a two-part study with ostensibly unrelated segments and was conducted using Qualtrics survey software. In the first part, participants were given a writing task. To activate the motivation for money (money condition), participants came up with three ways to invest $£ 20,000$ of seed money. For this, they had to outline specific plans about what they would do with the money (i.e. steps of their investment plans and expected profits). In the control condition, participants came up with three ways to get to the current location (i.e. the public place in central London) from where they lived (i.e. their residential location). This involved the description of specific routes they would take, the places they would go past and the time each route would take. In both conditions, participants were required to write at least 200 words. To measure social power, participants reported after the writing task how much control and influence they had experienced over other people in the scenario described, using 9-point Likert scales ranging from 1 (not at all) to 9 (extremely).

The second part of the study consisted of a face evaluation task in which participants had to judge facial stimuli that ranged from human realistic to artificial on mental states capacities. Given that the notion of mental state includes both cognitive abilities and fundamental human experiences (Gray, Gray, \& Wegner, 2007), participants evaluated each image on two mind attributes, namely the capacity a) to think and plan (i.e. agency), and b) to feel pain (i.e. experience, see Nussbaum, 1995; Gray et al., 2012). Stimulus evaluation was blocked for each attribute, with all 27 images (i.e. 9 morph level x 3 face exemplars) presented in each block. Ratings were made on 7-point Likert scales, with response options ranging from 1 (definitely not able to feel pain; definitely does not have a mind) to 7 (definitely able to feel pain; definitely has a mind). The ordering of the two blocks as well as the facial stimuli within each block were randomized. Finally, participants answered the same three questions about their socioeconomic status as in Studies 1 and 2. 


\section{Results and Discussion}

One mental state attribution score was obtained by averaging the ratings of experience and agency across the three facial identities for each morph level (Cronbach's $\alpha s>.86)$. We further linearly transformed the original ratings from the 7-point Likert scales into scores ranging from 0 to 1 (with higher scores indicating greater mind attribution). A repeated measures analysis of variance (RM-ANOVA) with condition (money, control) as a betweensubjects factor and morph level $(1-9)$ as a within-subjects factor was performed on the standardized scores of mind attribution. The Greenhouse-Geisser adjustment to the degrees of freedom was applied to all univariate analyses. Participants' gender was excluded from the analyses due to lack of any significant effects of this variable in preliminary tests $(p s>.37)$.

As predicted, a significant main effect emerged for condition, $F(1,83)=9.09, p=$ $.003, \eta_{\mathrm{p}}{ }^{2}=.099$, showing that money as a motivator generally decreased participants' tendency to attribute mental capacities to the target faces $\left(M_{\text {money }}=0.42\right.$ vs. $\left.M_{\text {control }}=0.49\right)$.

The subjective feeling of influence was higher in the money condition $(M=5.81, S D$ $=1.99)$ compared to the control condition $(M=4.33, S D=2.71), t(83)=2.88, p=.005, d=$ 0.62). In an analysis of covariance (ANCOVA) with social power (control, influence) and socioeconomic status as covariates, the effect of condition (money vs. control) however remained significant for mental state attribution, $F(1,78)=11.2, p=.001, \eta_{\mathrm{p}}{ }^{2}=.13$.

To calculate the threshold in participants' attribution of human traits, psychometric curves for pain and mind were obtained by fitting the standardized scores with a Gaussian distribution in GraphPad Prism 6 (GraphPad Software Inc., California, USA) (see $R^{2}$ in Figure 1B for overall fit indexes of the model). The Point of Subjective Equality (PSE) was derived from the intersection of the fitted curve with the midpoint of the measure (see horizontal line at value 0.5 in Figure 1B). Theoretically, the PSE value should correspond to morph 5 on the abscissa where the face is half animate/inanimate (50\%). As can be seen in Figure 1B, 
significant differences in the PSE values occurred between the two groups for mental state attribution, $U=562, p=.004\left(M d n_{\text {money }}=5.76 \text { vs. } M d n_{\text {control }}=5.29\right)^{2}$, with participants' PSE being closer to the human endpoint when they had been thinking about money. For participants in the money condition the target faces therefore needed to be more realistic in order to be perceived as human than for those who were in the control condition.

\section{Study 4: Destructive Behavior towards a Plush Toy}

The previous experiment demonstrated that money as a motivational force led to greater denial of mental state capacities in human targets, with more stringent thresholds in mind attribution. In the final study, we explored whether this finding extends to non-human targets such as animals. Whilst the perception of mental capacities in animals may be generally weaker than that in humans (Bastian et al., 2012), the motivational factors in mental state attribution may be similar (e.g. Epley, Waytz, Akalis, \& Cacioppo, 2008), allowing for the effects of money to generalize across species.

In addition, we tested whether love of money affects the violability dimension of objectification (Nussbaum, 1995) in terms of increased unethical intentions. For this, a novel behavioral task was developed which allowed us to directly assess destructive tendencies toward a plush toy. If mind perception acts as the driving force, we expected the effect of money in the treatment of the plush toy to be significantly mediated by attributed levels of mental states to nonhuman animals. To rule out explanations based on individual differences in the value attached to material objects, we included a measure of materialism.

\section{Method}

Participants. Eighty-seven $\left(M_{\text {age }}=33.2, S D=8.62\right)$ male participants $(74 \%$ Caucasian, $12 \%$ Asian, and 14\% Hispanic) were recruited from a public library in central London and took part in the study on a voluntary basis. We focused on men as the study 
sample of interest to control for potential gender differences in destructive inclinations (Archer, 2004). Data from five participants were excluded due to failure to follow instructions in the writing task. Participants were randomly assigned to one of two conditions (money vs. control), resulting in forty-one people in each condition. Informed consent was obtained from all people prior to their participation.

Stimuli. Seven animals of varying intelligence levels that rarely qualify as pets or food products were chosen from previous work on mind perception (e.g. Bastian et al., 2012; Morewedge, Preston, \& Wegner, 2007) and included a pigeon, lion, antelope, turtle, squirrel, frog, and butterfly. All animals were presented as color images on white background (400 x 300 pixels) as selected from the Internet.

Design and Procedure. The study was described as a three-part study with ostensibly unrelated segments and was conducted using Qualtrics survey software. Participants first completed the same writing task (money condition: strategies to increase seed money of $£ 20,000$; control condition: daily travel plans) as in Study 3. As a control measure of materialism, we then asked participants to answer two questions from the short version of the Material Values Scale (Richins, 2004) which assesses the extent to which success is defined in terms of material things ("I admire people who own expensive homes, cars, and clothes") and material possessions are seen as central to one's life ("Buying things gives me a lot of pleasure"). Items were endorsed on 7-point Likert scales, where $1=$ strongly disagree and $7=$ strongly agree.

In the second part of the study, we measured the degree of mental state attribution. In particular, participants rated the extent to which each of the seven animals 1) possessed cognitive abilities (i.e., self-control, morality, memory, emotion recognition, and planning) and 2) was capable of fundamental experience (i.e., hunger, fear, pleasure, pain, and rage) 
using 7-point Likert scales $(1=$ definitely not, $7=$ definitely yes $)$. Stimulus and item order was randomized.

The third part was construed as an independent consumer test that aimed to assess a new product available for purchase in the coming months. In order to provide appropriate feedback to the manufacturer participants were encouraged to evaluate the quality of a plush toy (teddy bear of approx. 12 x $9 \mathrm{~cm}$ size, see Figure 2) on several dimensions. Material checks were performed at three stages and required participants first to cut off various body parts (i.e., arms, legs and ears) with the use of scissors, then cut through the main body, and finally remove the eyes by pulling them out. To detract from the main study hypothesis, participants rated the material at each stage on elasticity, softness and ease of manipulation, respectively, using 7-point Likert scales ranging from 1 (very inflexible/scratchy/not easy at all) to 7 (very flexible/soft/very easy). Lastly, they estimated the price of the product (eight options from $£ 0.1$ to $£ 3$ ) and feelings of guilt of what they had done on a Likert scale ranging from 1 (not guilty at all) to 7 (very guilty).

Behavioral Coding. A coding scheme was developed to measure three types of destructive behavior on graduated scales: a) number of body parts fully removed (including eye/s, nose, ear/s, whole arm/s, whole leg/s, part of arm/leg, and head), b) size of cuts through the body/body parts $(1$ - slightly to 5 - extremely severe $)$, and c) amount of inner material removed (1-very little to 3 - a lot). Each behavior was assigned a certain weight in the calculation of the product's damage ${ }^{3}$. A total damage score was derived from the sum of all scores given across the three dimensions, ranging from 0 to 23 , with higher scores reflecting more destructive behavior. Two raters who were blind to the type of condition (money, control) independently followed the coding scheme. Interrater agreement was very high, $\kappa=$ .96 (Hayes \& Krippendorff, 2007), demonstrating good reliability. 


\section{Results and Discussion}

Animal Ratings. An overall mental attribution score was obtained by averaging the ratings of cognitive abilities and fundamental experience across all seven animals (Cronbach's $\alpha=.88)$. An independent sample t-test showed that participants in the money condition $(M=$ $4.04, S D=1.06)$ were significantly less likely to attribute mental states to these animals than those in the control condition $(M=4.65, S D=1.01), t(80)=-2.67, p=.009, d=-0.60$.

Behavioral Task. Composite damage scores by the two coders were averaged and square-root transformed to reduce skewness. As predicted, thinking about money made participants behave more destructively by causing greater damage to the plush toy $(M=2.35$, $S D=0.82)$ than thinking about daily travel plans $(M=1.53, S D=1.34), t(80)=3.37, p=$ $.001, d=0.74$ (see Figure 2 for examples). There was no significant difference between the two conditions in terms of price estimates for the product, $t(80)=-0.44, p=.66, d=-0.10$, and feelings of guilt, $t(80)=0.19, p=.85, d=0.04$. Similarly, perceived elasticity, softness and ease of manipulation did not vary with the type of condition, $/ t / \mathrm{s}<0.99, p \mathrm{~s}>.32$. The damage done to the plush toy was therefore unlikely to be due to the way in which the product was seen. When controlling for materialism (success, centrality) in an analysis of covariance (ANCOVA), the effect of condition (money, control) on mental state attribution, $F(1,78)=$ $6.39, p=.014, \eta_{\mathrm{p}}^{2}=.076$, as well as on destructive behavior remained significant, $F(1,78)=$ $10.4, p=.002, \eta_{\mathrm{p}}{ }^{2}=.12$, excluding explanations based on dispositional factors.

Mediation Analysis. In order to examine whether money as a motivational source leads to destructive behavior via deprived perception of mental states, we conducted mediation analyses. As shown in Figure 3, condition (money, control) predicted mental state attribution, as well as destructive behavior. Similarly, mental state attribution predicted destructive behavior. When controlling for mental state attribution, the effect of condition (money, control) on destructive behavior was reduced. A bootstrapped analysis (Preacher \& 
Hayes, 2008; 5000 re-samples) revealed that the 95\% confidence interval for the indirect effect did not include zero, $[\mathrm{CI}=-.39 \text { to }-.025]^{4}$. This indicates that the unethical behavior caused by money was partially mediated by the decreased mental state attribution. In sum, Study 4 showed that money led to lower mind attributions of animals, with perceptions of mental states accounting for the subsequent unethicality brought about by money.

\section{General Discussion}

Whilst the negative influence of money in interpersonal relationships is well known, little attention has been given to the underlying social cognitive mechanisms. Recent empirical evidence has pointed toward objectification in the economic domain (e.g. Andrighetto et al., 2016; Gruenfeld et al., 2008; Harris et al., 2014), however, the specific role of money remained unexplored. The present research aimed to fill this empirical gap by examining whether objectification results from the love of money, and can account for the unethical outcomes brought about by money. Across four studies, we showed that the love and importance attached to money correlated positively with the tendency to construe social relationships in terms of perceived instrumentality (Study 1). Temporarily eliciting an affective state of being rich led participants to prefer targets that were of direct use to their goal achievement (Study 2). Thinking about strategies to increase seed money further resulted in the deprival of mental capacities (i.e., cognitive abilities and fundamental experience) of irrelevant targets, including humans (Study 3) and animals (Study 4). This lack of perceived mental states partially mediated the effects of money on subsequent destructive behavior (Study 4).

To our knowledge, this is the first paper to reveal a link between the love of money and objectification. These findings have important implications for research in several ways. Firstly, they contribute to an emerging line of work on objectification in non-sexual contexts. 
Up to now, most evidence has been gathered within the sexual realm (see Gervais et al, 2012; Loughnan, et al., 2010; Vaes et al., 2011), with only a few studies focusing on objectification in money-related domains, such as work settings and labor markets (e.g. Andrighetto et al., 2016; Harris et al., 2014). While these provide important insights into economic objectification under capitalism they do not allow for the role of money to be studied separate from other potential confounding variables such as social power and status. Up to now, explanations for the detrimental effects of money on interpersonal harmony have mainly relied on market-pricing mode (Kouchaki et al., 2013; Fiske, 1992; Vohs et al., 2008) and offer accounts that describe a mindset of calculation with a focus on personal gain and goal achievement (Fiske, 1992; Vohs et al., 2008). However, they do not directly address the link between money and objectification as a social cognitive process. The present research combines the two fields by showing that objectification emerges with the sole desire for money and can partially explain the unethical outcomes brought about by money.

By employing a variety of paradigms, we demonstrated the impact of money as a motivational and affective source. This also involved the development of a novel behavioral task for evaluating actual destructive tendencies towards a plush toy. Besides its role as an implicit measure (thereby avoiding desirability effects inherent in self-reports), it can function as a state-level indicator of violable behavior. In addition, unethical intentions due to money have often been associated with the attainment of economic benefits (i.e., lying or cheating to obtain more money, Kouchaki et al., 2013). Given that equivalent effects were found in the present research without such monetary reward (Study 4), we consider mental state deprivation to be crucial for facilitating moral disengagement (see Bandura, 1999; Gray et al., 2012). This denial of mental states may be particularly relevant in cases where immoral behavior cannot be attributed to an external motivation (e.g. money incentive). 
Despite the novelty of the present work, it is worth pointing out some limitations and directions for future research. While the current findings are in line with predictions by market-pricing mode, they may not be explained purely from a functionalist perspective (i.e. maximization of gain and minimization of cost). Communal mode mentality, in which kindness and altruism are seen as central to social relations, lies at the opposite end of market pricing mode (Fiske, 1992; Gasiorowska, Chaplin, Zaleskiewicz, Wygrab, \& Vohs, 2016). It has been demonstrated that money brings about behavior that is consistent with marketpricing mode (i.e. self-gain and goal-achievement) while it impairs behavior consistent with the communal mode (i.e. pro-sociality and generosity; Gasiorowska et al., 2016). It is therefore equally likely that mind deprivation is caused by a reduced motivation for social bonding and intimacy (Wheatley, Kang, Parkinson, \& Looser, 2012) due to the de-activation of the communal mode. Although we do not consider these two processes to be mutually exclusive, future studies could examine their relative contributions. This would also allow for an analysis of the conditions under which the detrimental effects of money on interpersonal relations reverse (e.g. when mind perception proves beneficial for goal attainment; when money is deliberately used for altruistic purposes, such as donation).

In the present research, similar effects of money were found using different dependent measures. Nonetheless, it is possible that the love of money primed concepts other than those discussed in this paper. For example, there is evidence showing that reminders of money make people work harder on competency tasks (e.g. Vohs et al, 2006, 2008; Gasiorowska et al., 2016). Such performance motivation could have made participants in Study 2 focus more on the partner's competence which inevitably serves as a confound of usefulness. Higher motivation to perform in a task might also explain why mind deprivation in Study 4 only partially mediated the effects of money on destructive behavior. Alternatively, the affective state of being rich (Study 2) could have primed a high-status position which in turn led 
participants to prefer a partner with similar high-status traits (i.e. competent but cold).

Although the effects of money were shown to go beyond participants' social power and status, future studies might include additional measures to control for potential confounds. The two dimensions of competence and warmth (Fiske, Cuddy, Glick, \& Xu, 2002) seem particularly relevant in this case.

In this paper, we have shown that objectification increases with money as an affective and motivational source. Specifically, the love of money led to a greater tendency to favor targets based on their instrumental use and deprive irrelevant others of their mental states. Such diminished mind perception further accounted for the unethicality brought about by money. The present work constitutes a first step in showing that objectification (i.e. mental state attribution) acts as the social cognitive link between money and immoral behavior. Continuing this type of research will allow for clear predictions about how and when money leads to detrimental outcomes. 


\section{References}

Adler, N. E., Epel, E. S., Castellazzo, G., \& Ickovics, J. R. (2000). Relationship of subjective and objective social status with psychological and physiological functioning: Preliminary data in healthy, White women. Health Psychology, 19, 586-592. doi: $10.1037 / 0278-6133.19 .6 .586$

Anderson, C., \& Galinsky, A. D. (2006). Power, optimism, and risk-taking. European Journal of Social Psychology, 36, 511-536. doi: 10.1002/ejsp.324.

Andrighetto, L., Baldissarri, C., and Volpato, C. (2016) (Still) Modern Times: Objectification at work. European Journal of Social Psychology, doi: 10.1002/ejsp.2190.

Archer, J. (2004). Sex differences in aggression in real-world settings: a meta-analytic review. Review of General Psychology, 8, 291-322. doi: 10.1037/1089-2680.8.4.291.

Baker, P. M., \& Hagedorn, R. B. (2008). Attitudes to money in a random sample of adults: Factor analysis of the MAS and MBBS scales, and correlations with demographic variables. The Journal of Socio-Economics, 37, 1803-1814. doi:10.1016/j.socec.2008.02.004.

Baldissarri, C. R. I. S. T. I. N. A., Andrighetto, L. U. C. A., \& Volpato, C. H. I. A. R. A. (2014). When work does not ennoble man: Psychological consequences of working objectification. Testing, Psychometrics, Methodology in Applied Psychology, 21, 327339. doi:10.4473.

Bandura, A. (1999). Moral disengagement in the perpetration of inhumanities. Personality and Social Psychology Review, 3, 193-209. doi: 10.1207/s15327957pspr0303_3.

Bastian, B., Loughnan, S., Haslam, N., \& Radke, H. R. (2012). Don’t mind meat? The denial of mind to animals used for human consumption. Personality and Social Psychology Bulletin, 38, 247-256. doi: 10.1177/0146167211424291. 
Baumeister, R. F., \& Vohs, K. D. (2016). The meanings of money: Behavioral, interpersonal, cognitive, motivational, and affective consequences of money-related thoughts. Unpublished manuscript. University of Minnesota, Minneapolis, Minnesota, United States.

Berscheid, E., \& Reis, H. T. (1998). Attraction and close relationships. In D. T. Gilbert, S. T. Fiske, \& G. Lindzey (Eds.), The handbook of social psychology (4th ed., pp. 193-281). New York: McGraw-Hill.

Blauner, B. (1964). Alienation and freedom: The factory worker and his industry. Chicago: University of Chicago Press.

Caruso, E. M., Mead, N. L., \& Vohs, K. D. (2009). There's no “you” in money: Thinking of money increases egocentrism. In A. L. McGill \& S. Shavitt (Eds.), Advances in consumer research (pp. 206-209). Duluth, MN: Association for Consumer Research.

Epley, N., Waytz, A., Akalis, S., \& Cacioppo, J. T. (2008). When we need a human: Motivational determinants of anthropomorphism. Social Cognition, 26, 143-155. doi: 10.1521/soco.2008.26.2.143.

Fiske, A. P. (1992). The four elementary forms of sociality: framework for a unified theory of social relations. Psychological Review, 99, 689-723.

Fiske, S. T., Cuddy, A. J., Glick, P., \& Xu, J. (2002). A model of (often mixed) stereotype content: competence and warmth respectively follow from perceived status and competition. Journal of Personality and Social Psychology, 82, 878-902. doi: $10.1037 / 0022-3514.82 .6 .878$.

Gasiorowska, A., Chaplin, L. N., Zaleskiewicz, T., Wygrab, S., \& Vohs, K. D. (2016). Money Cues Increase Agency and Decrease Prosociality Among Children Early Signs of Market-Mode Behaviors. Psychological Science, 27, 331-344. doi: $10.1177 / 0956797615620378$. 
Gervais, S. J., Vescio, T. K., Förster, J., Maass, A., \& Suitner, C. (2012). Seeing women as objects: The sexual body part recognition bias. European Journal of Social Psychology, 42, 743-753. doi: 10.1002/ejsp.1890.

Gino, F., \& Pierce, L. (2009). The abundance effect: Unethical behavior in the presence of wealth. Organizational Behavior and Human Decision Processes, 109, 142-155. doi:10.1016/j.obhdp.2009.03.003.

Gray, H. M., Gray, K., \& Wegner, D. M. (2007). Dimensions of mind perception. Science, 315, 619. doi: 10.1126/science.1134475.

Gray, K., Young, L., \& Waytz, A. (2012). Mind perception is the essence of morality. Psychological Inquiry, 23, 101-124. doi: 10.1080/1047840X.2012.651387.

Gruenfeld, D. H., Inesi, M. E., Magee, J. C., \& Galinsky, A. D. (2008). Power and the objectification of social targets. Journal of Personality and Social Psychology, 95, 111127. doi: 10.1037/0022-3514.95.1.111.

Gwinn, J. D., Judd, C. M., \& Park, B. (2013). Less power= less human? Effects of power differentials on dehumanization. Journal of Experimental Social Psychology, 49, 464470. doi:10.1016/j.jesp.2013.01.005.

Hall, J. A., Mast, M. S., \& Latu, I. M. (2015). The vertical dimension of social relations and accurate interpersonal perception: A meta-analysis. Journal of Nonverbal Behavior, 39, 131-163. doi 10.1007/s10919-014-0205-1.

Harris, L. T., Lee, V. K., Capestany, B. H., \& Cohen, A. O. (2014). Assigning economic value to people results in dehumanization brain response. Journal of Neuroscience, Psychology, and Economics, 7, 151-163. doi: 10.1037/npe0000020.

Haslam, N. (2006). Dehumanization: An integrative review. Personality and Social Psychology Review, 10, 252-264. doi: 10.1207/s15327957pspr1003_4. 
Hayes, A. F., \& Krippendorff, K. (2007). Answering the call for a standard reliability measure for coding data. Communication Methods and Measures, 1, 77-89. doi: $10.1080 / 19312450709336664$.

Heyman, J., \& Ariely, D. (2004). Effort for payment a tale of two markets. Psychological Science, 15, 787-793. doi: 10.1111/j.0956-7976.2004.00757.x.

Inesi, M. E., Lee, S. Y., \& Rios, K. (2014). Objects of desire: Subordinate ingratiation triggers self-objectification among powerful. Journal of Experimental Social Psychology, 53, 19-30. doi:10.1016/j.jesp.2014.01.010.

Kouchaki, M., Smith-Crowe, K., Brief, A. P., \& Sousa, C. (2013). Seeing green: Mere exposure to money triggers a business decision frame and unethical outcomes. Organizational Behavior and Human Decision Processes, 121, 53-61. doi:10.1016/j.obhdp.2012.12.002.

Kraus, M. W., Côté, S., \& Keltner, D. (2010). Social class, contextualism, and empathic accuracy. Psychological Science, 99, 771-784. doi: 10.1177/0956797610387613.

Krumhuber, E. G., Swiderska, A., Tsankova, E., Kamble, S. V., \& Kappas, A. (2015). Real or artificial? Intergroup biases in mind perception in a cross-cultural perspective. PloS One, 10(9), e0137840. doi:10.1371/journal.pone.0137840.

Lee, L., Lee, M. P., Bertini, M., Zauberman, G., \& Ariely, D. (2015). Money, time, and the stability of consumer preferences. Journal of Marketing Research, 52, 184-199. doi: http://dx.doi.org/10.1509/jmr.10.0386.

Lim, V. K., \& Teo, T. S. (1997). Sex, money and financial hardship: An empirical study of attitudes towards money among undergraduates in Singapore. Journal of Economic Psychology, 18, 369-386. doi:10.1016/S0167-4870(97)00013-5.

Loughnan, S., Haslam, N., Murnane, T., Vaes, J., Reynolds, C., \& Suitner, C. (2010). Objectification leads to depersonalization: The denial of mind and moral concern to 
objectified others. European Journal of Social Psychology, 40, 709-717. doi: 10.1002/ejsp.755.

Ma-Kellams, C., \& Blascovich, J. (2013). The ironic effect of financial incentive on empathic accuracy. Journal of Experimental Social Psychology, 49, 65-71. doi:10.1016/j.jesp.2012.08.014.

Marx, K. (1844) Economic and Philosophical Manuscripts of 1844, In: The Marx-Engels Reader. Edited by Robert Tucker. New York: Norton \& Company, 1978.

Molinsky, A. L., Grant, A. M., \& Margolis, J. D. (2012). The bedside manner of homo economicus: How and why priming an economic schema reduces compassion. Organizational Behavior and Human Decision Processes, 119, 27-37. doi:10.1016/j.obhdp.2012.05.001.

Morewedge, C. K., Preston, J., \& Wegner, D. M. (2007). Timescale bias in the attribution of mind. Journal of Personality and Social Psychology, 93, 1-11. doi: 10.1037/00223514.93.1.1.

Nussbaum, M. C. (1995). Objectification. Philosophy \& Public Affairs, 24, 249-291.

Nussbaum, M. C. (1999). Sex and social justice. In M. C. Nussbaum (Ed.), Objectification (pp. 213-239). New York: Oxford University Press.

Papadaki, E. L. (2007). Sexual objectification: From Kant to contemporary feminism. Contemporary Political Theory, 6, 330-348. doi: 10.1057/palgrave.cpt.9300282.

Penn, D. C., \& Povinelli, D. J. (2007). Causal cognition in human and nonhuman animals: A comparative, critical review. Annual Review of Psychology, 58, 97-118. doi: 10.1146/annurev.psych.58.110405.085555.

Pfeffer, J., \& DeVoe, S. E. (2009). Economic evaluation: The effect of money and economics on attitudes about volunteering. Journal of Economic Psychology, 30, 500-508. doi:10.1016/j.joep.2008.08.006. 
Piff, P. K., Stancato, D. M., Côté, S., Mendoza-Denton, R., \& Keltner, D. (2012). Higher social class predicts increased unethical behavior. Proceedings of the National Academy of Sciences, 109, 4086-4091. doi: 10.1073/pnas.1118373109.

Preacher, K. J., \& Hayes, A. F. (2008). Asymptotic and resampling strategies for assessing and comparing indirect effects in multiple mediator models. Behavior Research Methods, 40, 879-891. doi: 10.3758/BRM.40.3.879.

Richins, M. L. (2004). The material values scale: Measurement properties and development of a short form. Journal of Consumer Research, 31, 209-219. doi: 10.1086/383436.

Tang, T. L. P., \& Chen, Y. J. (2008). Intelligence vs. wisdom: The love of money, Machiavellianism, and unethical behavior across college major and gender. Journal of Business Ethics, 82, 1-26. doi: 10.1007/s10551-007-9559-1.

Tang, T. L. P., \& Chen, Y. J., \& Sutarso, T. (2008). Bad apples in bad (business) barrels: The love of money, Machiavellianism, risk tolerance, and unethical behavior. Management Decision, 46, 243-263. doi: 10.1108/00251740810854140.

Tang, T. L. P., \& Chiu, R. K. (2003). Income, money ethic, pay satisfaction, commitment, and unethical behavior: Is the love of money the root of evil for Hong Kong employees? Journal of Business Ethics, 46, 13-30. doi: 10.1023/A:1024731611490.

Vaes, J., Paladino, P., \& Puvia, E. (2011). Are sexualized women complete human beings? Why men and women dehumanize sexually objectified women. European Journal of Social Psychology, 41, 774-785. doi: 10.1002/ejsp.824.

Vohs, K. D. (2015). Money priming can change people's thoughts, feelings, motivations, and behaviors: An update on 10 years of experiments. Journal of Experimental Psychology: General, 144, e86-e93. doi: 10.1037/xge0000091.

Vohs, K. D., Mead, N. L., \& Goode, M. R. (2006). The psychological consequences of money. Science, 314, 1154-1156. doi: 10.1126/science.1132491. 
Vohs, K. D., Mead, N. L., \& Goode, M. R. (2008). Merely activating the concept of money changes personal and interpersonal behavior. Current Directions in Psychological Science, 17, 208-212. doi: 10.1111/j.1467-8721.2008.00576.x.

Wheatley, T., Kang, O., Parkinson, C., \& Looser, C. E. (2012). From mind perception to mental connection: Synchrony as a mechanism for social understanding. Social and Personality Psychology Compass, 6, 589-606. doi: 10.1111/j.1751-9004.2012.00450.x.

Wilson, D. S., Near, D., \& Miller, R. R. (1996). Machiavellianism: a synthesis of the evolutionary and psychological literatures. Psychological Bulletin, 119, 285-299. doi: 10.1037/0033-2909.119.2.285. 


\section{Footnotes}

${ }^{1}$ Participants who failed to write less than 120 words or come up with at least two strategies/plans were excluded for not meeting the task requirement.

${ }^{2}$ Due to violation of the assumptions of homogeneity of variance and normal distribution, non-parametric tests such as the Mann-Whitney U test were used.

${ }^{3}$ Weight coefficients were for: a) number of body parts fully removed: 5 points for the head, 1 point for whole arm/s and whole leg/s, 0.5 points for part of arm/leg and all remaining body parts (i.e. ear/s, nose, eye/s); b) size of cuts through the body/body parts: 1 point for the head and main body, 0.2 points for arms and legs; c) amount of inner material removed: 1 point.

${ }^{4}$ When controlling for materialism (success, centrality) in the mediation model, mental state attribution still partially mediated the effect of money on destructive behavior. The mediation remained significant, $\mathrm{CI}=-.35$ to $-.0048,95 \%$ confidence interval, 5000 resamples (Preacher \& Hayes, 2008). 


\section{Running head: MONEY AND OBJECTIFICATION}

Table 1. Correlations Among the Measures used in Study 1

\begin{tabular}{|c|c|c|c|c|c|c|c|c|c|c|c|c|c|c|}
\hline Variable & $M(S D)$ & 1 & 2 & 3 & 4 & 5 & 6 & 7 & 8 & 9 & 10 & 11 & 12 & 13 \\
\hline 1. Objectification & $3.15(0.73)$ & & & & & & & & & & & & & \\
\hline $\begin{array}{l}\text { 2. Money } \\
\text { (obsession) }\end{array}$ & $2.43(0.98)$ & $.489 * *$ & & & & & & & & & & & & \\
\hline 3. Money (power) & $3.83(1.15)$ & $.313^{* *}$ & $.596 * *$ & & & & & & & & & & & \\
\hline 4. Money (budget) & 4.14. (1.22) & .114 & .128 & .086 & & & & & & & & & & \\
\hline $\begin{array}{l}\text { 5. Money } \\
\text { (achievement) }\end{array}$ & $3.15(1.25)$ & $.273^{* *}$ & $.516^{* *}$ & $.583^{* *}$ & .111 & & & & & & & & & \\
\hline $\begin{array}{l}\text { 6. Money } \\
\text { (evaluation) }\end{array}$ & $3.74(1.27)$ & .106 & $.285^{* *}$ & $.377 * *$ & .010 & .088 & & & & & & & & \\
\hline 7. Money (anxiety) & $3.16(1.24)$ & $.188^{*}$ & $.395 * *$ & $.417 * *$ & .176 & $.264 * *$ & $.570 * *$ & & & & & & & \\
\hline $\begin{array}{l}\text { 8. Money } \\
\text { (retention) }\end{array}$ & $4.16(1.24)$ & .083 & -.018 & .126 & $.245^{* *}$ & .115 & $.330 * *$ & $.295^{* *}$ & & & & & & \\
\hline $\begin{array}{l}\text { 9. Money (non- } \\
\text { generosity) }\end{array}$ & $4.52(1.25)$ & .096 & $.313 * *$ & $.322 * *$ & .147 & $.321 * *$ & .079 & .152 & .090 & & & & & \\
\hline $\begin{array}{l}\text { 10. Money (power- } \\
\text { prestige) }\end{array}$ & $2.42(0.88)$ & $.490 * *$ & $.724 * *$ & $.631 * *$ & .015 & $.575^{* *}$ & $.342 * *$ & $.490 * *$ & .115 & $.246^{* *}$ & & & & \\
\hline 11. Education & $7.20(2.14)$ & -.110 & .091 & .157 & -.062 & .079 & -.175 & -.020 & $-.297 * *$ & .029 & .021 & & & \\
\hline 12. Social Status & $5.03(1.67)$ & .033 & .034 & .006 & .038 & .074 & $-.207 *$ & -.170 & -.081 & .046 & .032 & $.289 * *$ & & \\
\hline 13. Income & $6.36(4.13)$ & -.089 & .104 & .123 & -.035 & .050 & -.038 & -.164 & -.107 & $.187^{*}$ & .067 & .129 & $.313^{* *}$ & \\
\hline 14. Sense of power & $4.17(0.81)$ & .017 & .047 & .064 & $.237 * *$ & .038 & -.021 & .072 & -.128 & .064 & .010 & .089 & $.230 *$ & .011 \\
\hline
\end{tabular}

$* p<.05 \quad * * p<.01$ 
A

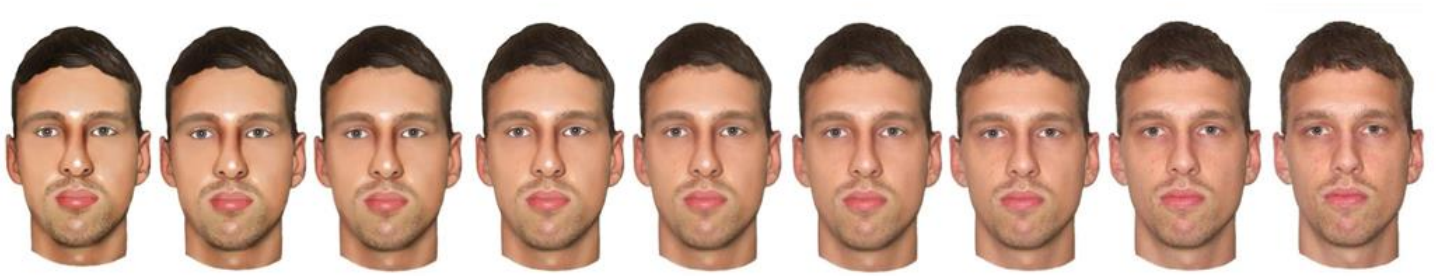

B

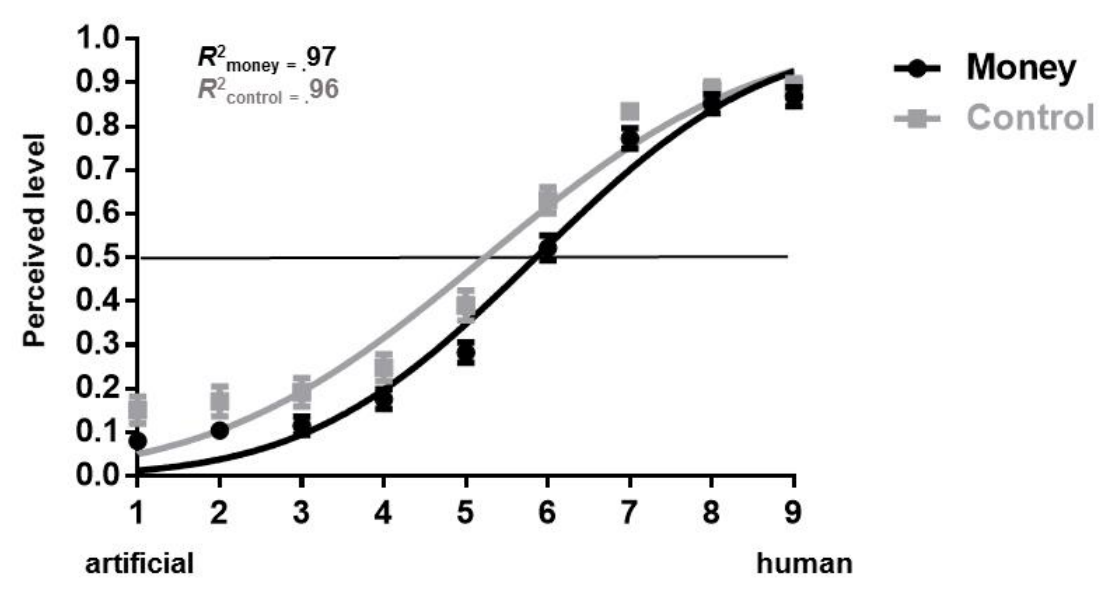

Figure 1. (A) Example of a facial target with 9 variants from artificial to human (right side) as used in Study 3. (B) Participants' level of mental state attribution at each point along the face morph continuum including error bars (SEM) and the fitted curves (solid lines) per measure. 


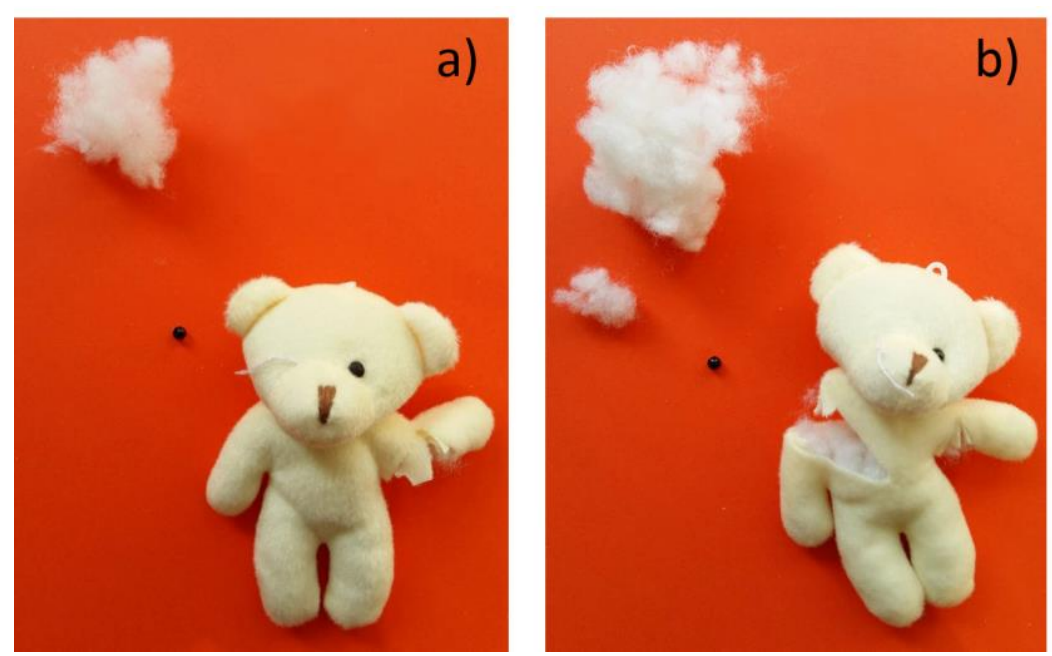

Figure 2. Amount of destructive behavior shown by a participant in the control condition (a) and money condition (b) in Study 4. 


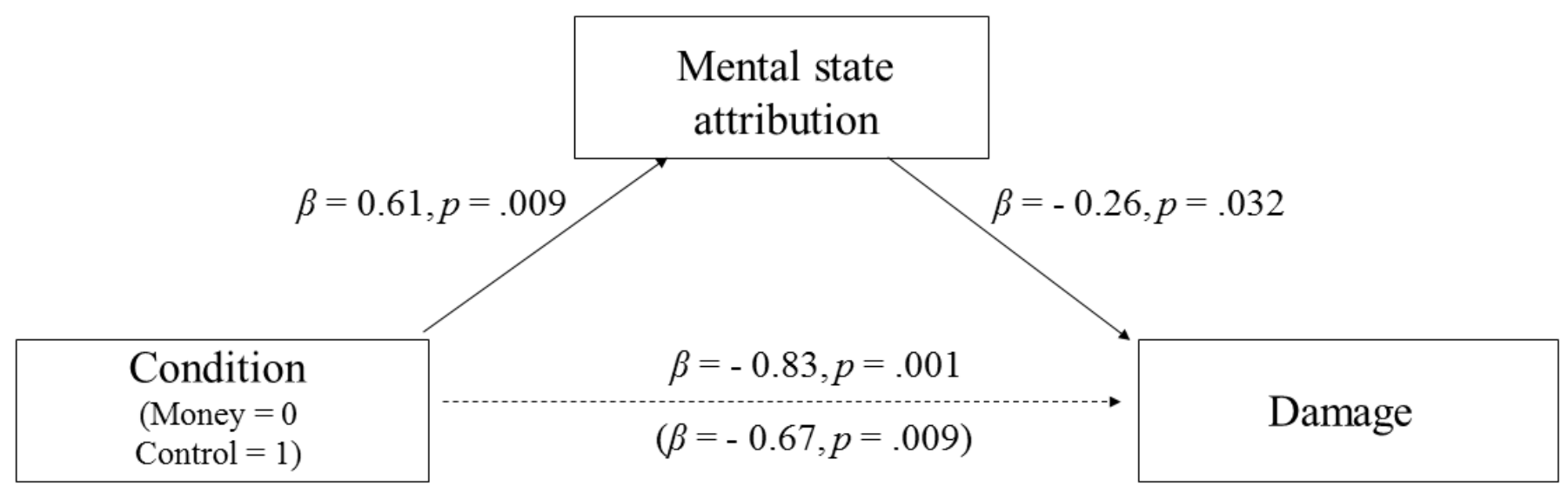

Figure 3. Mediation model for the effect of condition (money vs. control) on destructive behavior (total damage incurred) via mental state attribution, Study 4. Values for the indirect path (i.e. when controlling for the mediator) are shown in parenthesis. 
